\title{
ANALISIS PENERAPAN GOOD CORPORATE GOVERNANCE PADA PT. BANK ACEH SYARIAH CABANG KUTACANE
}

\author{
Rina Malahayati \\ Universitas Gunung Leuser Kutacane \\ diarieriena@gmail.com
}

\begin{abstract}
Good Corporate Governance at PT. Bank Aceh Syariah Kutacane Branch. The population of this study is Bank Aceh Syariah Kutacane Branch SouthEast Aceh Regency. The Observation of year is 2018. The data analysis technique used in this study is Reduction of data, Presentation of data and conclusion. The result of this research that the implementation of good corporate governance in PT. Bank Aceh Syariah branch of kutacane has been running and implementing wellness. Based on four principle namely Transparency, Accountability, Responsibility, and Fairness in accordance with the laws and the regulations implemented by Bank Indonesia.
\end{abstract}

Keyword: Good Corporate Governance, Transparency, Accountability, Responsibility, and Fairness

\section{PENDAHULUAN}

Pembahasan mengenai Good Corporate Governance bisa dimulai dari tahun 1999 karena pada tahun tersebut terjadi krisis ekonomi global dan banyak perusahaan yang tidak mampu menghadapi krisis karena kondisi keuangan yang tidak sehat. Krisis ekonomi yang terjadi tersebut menjadi tonggak pemahaman mengenai pentingnya penerapan GCG dan bukan hanya sebagai rujukan tetapi sudah menjadi keharusan (Ardy, 2016).

Dukungan terhadap penerapan GCG di Indonesia juga dilakukan oleh otoritas jasa keuangan (OJK) dan Indonesian Institute for Corporate Directorship (IICD) yang mengumpulkan data-data perusahaan untuk melakukan evaluasi terhadap penerapan GCG. Kedua institusi melakukan pemeringkatan perusahaan-perusahaan berdasarkan penerapan GCG setiap tahun. Pada tahun 2015 secara umum terdapat tiga perusahaan dengan predikat GCG terbaik, yaitu: PT Bank Danamon Indonesia Tbk, PT Bank CIMB Niaga Tbk, dan PT Aneka Tambang (Persero) Tbk (Idris, 2015). Apresiasi terhadap perusahaan-perusahaan yang menerapkan GCG dengan baik merupakan sebuah bentuk dukungan terhadap penerapan GCG di Indonesia. Temuan lain dari survei otoritas jasa keuangan (OJK) dan Indonesian Institute for Corporate Directorship (IICD) tahun 2015 bahwa jumlah emiten (perusahaan) yang telah memenuhi standar penerapan prinsip GCG sebanyak 571 perusahaan dan masih dibawah Singapura sebanyak 771 perusahaan dan Malaysia sebanyak 900 perusahaan (Idris, 2015).

Berdasarkan data ini juga bisa dijelaskan bahwa penerapan GCG di Indonesia belum menjadi yang terbaik dibandingkan negara-negara lain di Asia Tenggara dilihat dari jumlah perusahaan yang telah menerapkan standar GCG. Bahkan berdasarkan peringkatnya dari kualitas penerapan GCG tahun sebelumnya yaitu tahun 2014, menurut Muliaman Darmansyah Hadad (Ketua Dewan Komisioner OJK) bahwa rating penerapan GCG perusahaan di Indonesia secara keseluruhan masih menempati 
peringkat nomor dua dari bawah dari keseluruhan negara ASEAN.

Jumlah negara ASEAN sebanyak 10 negara dan berarti Indonesia adalah peringkat ke- 9 dari 10 negara (Ardhanareswari, 2014). Informasi yang ditekankan dari data ini bahwa perusahaanperusahaan di Indonesia masih perlu untuk terus meningkatkan kualitas penerapan GCG-nya, termasuk Perbankan di Indonesia.Bank Aceh adalah salah satu perbankan yang bergerak di bidang syariah. PT Bank Aceh Syariah yang memiliki motto "kepercayaan dan kemitraan" berkomitmen menerapkan Good Corporate Governance (GCG) dalam mewujudkan visi dan misinya, serta mewujudkan pertumbuhan dan akselerasi bisnis diseluruh segmen untuk menjadi Leading Regional Bank di masa mendatang. Manajemen Bank Aceh selalu memberikan dorongan agar semua karyawan konsisten dalam melaksanakan prinsip GCG untuk setiap pelaksanaan tugas dan tanggungjawab untuk pencapaian tujuan perusahaan.

Penerapan Tata Kelola Perusahaan yang baik (Good Corporate Governance/GCG) telah menjadi landasan kuat bagi Bank Aceh untuk menghadapi perubahan lingkungan bisnis di masa depan.

Segala keputusan strategis yang dilakukan oleh Dewan Komisaris dan Direksi selalu mempertimbangkan prinsip-prinsip GCG, yaitu Transparency, Accountability,

Responsibility,Profesional dan Fairness yang merupakan komitmen kuat Bank demi kepentingan pemegang saham dan para pemangku kepentingan lainnya (Bank Aceh, 2017).

Bank Aceh Syariah sudah menerapkan prinsip Good Corporate Governance, termasuk Bank Aceh Syariah cabang Kutacane. Fenomena yang menunjukkan bahwa Bank Aceh Syariah cabang Kutacane menjalankan prinsip GCG yaitu dengan menerapkan prinsip Responsibility pada kegiatan akhir bulan Mei 2018 kemarin, Bank Aceh cabang Kutacane gelar pasar murah di lima Kecamatan di Aceh Tenggara. Kelima Kecamatan itu, yakni Lawe Sigala-gala, Lawe Bulan, Lawe Alas, Bukit Tusam dan Kecamatan Darul Hasanah.Pasar murah Bank Aceh peduli itu langsung di motori oleh pimpinan Bank Aceh Syariah cabang Kutacane, Taufik Saleh dan stafnya. Untuk pasar murah tersebut mereka menyiapkan 500 paket di lima Kecamatan. Masingmasing paket, yaitu minyak goreng dua liter, gual pasir dua kilogram, sirup dua botol dan teh sari wangi. Ini adalah sebagai bentuk kepedulian Bank Aceh Syariah cabang Kutacane kepada masyarakat fakir miskin dalam bulan suci Ramadhan 1439 Hijriah (Luwi : aceh.tribunnews.com).Berdasarkan latar belakang masalah tersebut di atas, penelitian ini mencoba mengungkap serta menganalisis praktik penerapan prinsip-prinsipGood Corporate Governancepada PT. Bank Aceh Syariah Cabang Kutacane

\section{LANDASAN TEORI}

Good Corporate Governance

Menurut Sutedi (2017 : 01) Good Corporate Governance dapat didefinisikan sebagai suatu proses dan struktur yang digunakan oleh organ perusahaan (Pemegang Saham / Pemilik Modal, Komisaris / Dewan Pengawas dan Direksi) untuk meningkatkan keberhasilan usaha dan akuntabilitas perusahaan guna mewujudkan nilai pemegang saham dalam jangka panjang dengan tetap memperhatikan kepentingan stakeholder lainnya, berlandaskan peraturan perundang-undangan dan nilai-nilai etika. Dalam bukunya juga di jelaskan definisi menurut Cadbury 
Volume 8, Nomor 1, Februari, 2020

bahwa Good Corporate Governance adalah mengarahkan dan mengendalikan perusahaan agar tercapai keseimbangan antara kekuatan dan kewenangan perusahaan.

\section{Bank Syariah}

Bank Syariah adalah bank yang berdasarkan prinsip syariah (hukum Islam), yang dalam operasionalnya berpedoman kepada fatwa Dewan Syariah Nasional Majelis Ulama Indonesia (DSNMUI) (Mardani, 2015 : 12). Menurut Arwani (2016 : 15) Bank syariah adalah bank yang beroperasi sesuai dengan prinsip-prinsip syariah Islam, maksudnya adalah bank yang dalam operasinya mengikuti ketentuan-ketentuan syariah Islam, khususnya yang menyangkut tata cara bermuamalah secara islam.

\section{Prinsip-Prinsip Tata Kelola Secara Syariah}

\section{Keterbukaan (Transparancy)}

Menurut Basri dan Munandar (2013 : 235) Keterbukaan (Transparancy) adalah keterbukaan setiap kebijakan perusahaan. Prinsip transparansi ini sangat penting dalam pengelolaan suiatu perusahaan, terutama perusahaan yang akan atau telah melakukan penawaran umum (go publik), sehingga Barry A.K. Rider menyatakan "more disclosure will inevitably discourage wrong doing and abose" (keterbukaan akan mencegah kesalahan dan penyalahgunaan (Azheri, 2014 : 192).

Menurut Sutedi (2017 : 04) Transparancy, mewajibkan adanyasuatu informasi yang terbuka, tepat waktu, serta jelas dan dapat diperbandingkan, yang menyangkut keadaan keuangan, pengelolaan perusahaan, dan kepemilikan perusahaan.

Keterbukaan (Transparency) mengandung unsur pengungkapan (disclosure) dan penyediaan informasi secara tepat waktu,memadai,jelas dan akurat dan dapat diperbandingkan serta mudah diakses oleh pemangku kepentingan dan masyarakat (Bank Muamalat, 2017).

\section{Akuntabilitas (Accountabillity)}

Menurut Basri dan Munandar (2013 : 235) Akuntabillitas (Accountabillity) adalah kepastian tugas dan wewenang seluruh komponen perusahaan. Akuntabilitas merupakan dasar pengendalian sistem yangn efektif terhadap pelimpahan dan pembagian wewenang antara dewan komisaris, direksi, manajer eksekutif serta pemegang saham.

\section{Tanggung Jawab (Responsibility)}

Menurut Sutedi (2017 : 04) Responsibility (Pertanggungjawaban), memastikan dipatuhinya peraturan-peraturan serta ketentuan yang berlaku sebagai cermin dipatuhinya nilai-nilai sosial. Menurut Effendi (2016 : 15) Respopnsibility adalah kesesuaian pengelolaan perusahaan terhadap peraturan perundangan-undangan yang berlaku dan prinsipprinsip korporasi yang sehat.

Dengan menerapkan prinsip ini, diharapkan akan menyadarkan perusahaan bahwa dalam kegiatan operasionalnya, perusahaan juga mempunyai peran untuk bertanggung jawab kepada shareholders juga kepada stakeholderslainnya.

\section{Kewajaran (Fairness)}

Menurut Sutedi (2017 : 04) Fairness (keadilan), menjamin perlindungan hak para pemegang saham dan menjamin terlaksananya komitmen dengan para investor. Prinsip fairness lebih menekankan pada kejujuran, terutama untuk pemegang saham minoritas. Investor harus memiliki hak-hak yang jelas tentang kepemilikan dan sistem dari aturan dan hukuman yang dijalankan untuk melindungi hak-haknya (Sutedi, 2017 : 12). 
Kewajarandan kesetaraan (fairness)

KERANGKA KONSEPTUAL

mengandung unsur perlakuan yang adil dan

kesempatan yang sama sesuai dengan proporsinya

dalam memenuhi hak-hak pemangku kepentingan

berdasarkan perjanjian dan peraturan perundang-

undangan yang berlaku (Muamalat, 2017).

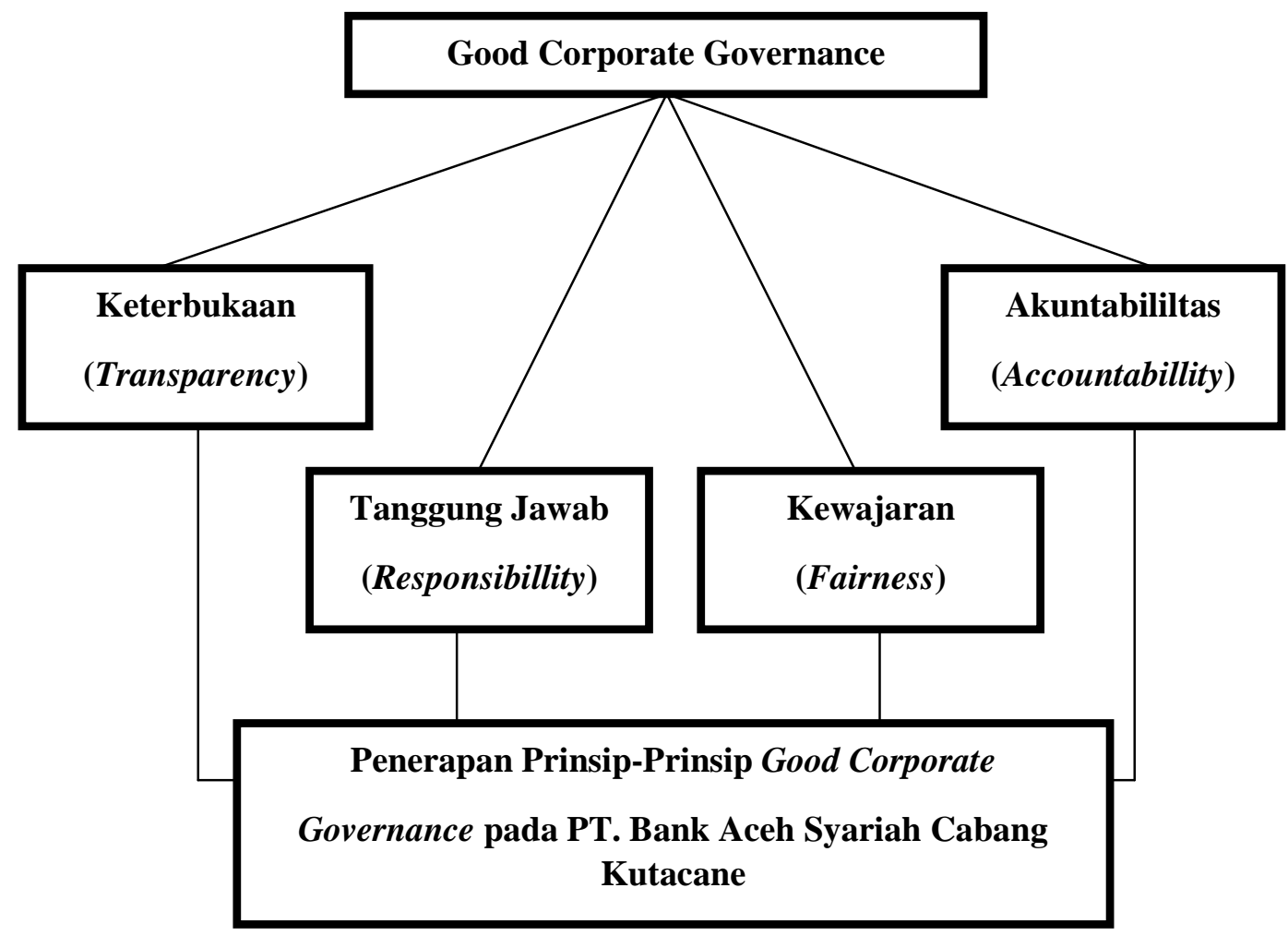

Gambar 1 Kerangka konseptual

\section{METODE PENELITIAN}

Populasi Penelitian

Menurut Sugiyono (2015:115), Populasi

adalah wilayah generalisasi terdiri atas obyek/subyek yang mempunyai kualitas dan karakteristik tertentu ditetapkan oleh peneliti untuk dipelajari dan kemudian ditarik kesimpulan. Maka dalam penelitian ini populasinya adalah Bank Aceh Syariah cabang Kutacane Kabupaten Aceh Tenggara.

\section{Data Penelitian}

Data primer yang digunakan dalam penelitian ini adalah wawancara semi terstruktur yaitu dimana dalam pelaksanaannya lebih bebas bila dibandingkan dengan wawancara terstruktur.Sumber data sekunder dalam penelitian ini adalah berupa kajian atas laporan tahunan, buku, jurnal-jurnal, dan artikel yang terkait dengan objek penelitian yang sedang dilakukan.

\section{Teknik Analisis Data}

Teknik analisis data yang digunakan dalam penelitian ini ada tiga tahapan yaitu menurut Sugiyono (2015 : 337-345) :

1. Reduksi Data

Reduksi data berarti merangkum, memilih hal-hal yang pokok, memfokuskan pada hal-hal yang 
Volume 8, Nomor 1, Februari, 2020

penting, dicari tema dan polanya. Dengan demikian data yang telah direduksi akan memberikan gambaran yang lebih jelas, dan mempermudah penelilti untuk melakukan pengumpulan data selanjutnya, dan mencarinya bila diperlukan.

2. Penyajian Data

Penyajian data bisa dilakukan dalam bentuk uraian singkat, bagan, hubungan antar kategori, flowchart dan sejenisnya. Yang paling sering digunakan untuk menyajikan data dalam penelitian kualitatif adalah dengan teks yang bersifat naratif. Dengan menyajikan data, maka akan memudahkan untuk memahami apa yang terjadi, merencanakan kerja selanjutnya berdasarkan apa yang telah dipahami tersebut.

3. Kesimpulan

Kesimpulan dalam penelitian kualitatif adalah merupakan temuan baru yang sebelumnya belum pernah ada. Temuan dapat berupa deskripsi atau gambaran suatu objek yang sebelumnya masih remang-remang atau gelap sehingga setelah diteliti menjadi jelas, dapat berupa hubungan kausal atau interaktif, hipotesis atau teori.

Penelitian ini menggunakan tehnik triangulasi sumber sebagai pengujian keabsahan data. Menurut Sugiyono (2015 : 372-374), triangulasi sumber adalah tehnik triangulasi yang digunakan untuk menguji kredibilitas data dengan cara mengecek data yang diperoleh melalui beberapa sumber. Data yang telah dianalisis kemudian dideskripsikan dan dikategorisasikan untuk kemudian menghasilkan suatu kesimpulan.

\section{HASIL DAN PEMBAHASAN}

Berdasarkan data yang diperoleh penulis melalui observasi dan wawancara dari 5 pegawai PT.
Bank Aceh Syariah cabang Kutacane yaitu Kepala Seksi Umum dan SDI, Kepala Seksi Funding, Kepala Seksi Operasional, Kepala Seksi Pembiayaan dan Kepala Seksi Legal \& Penyesuaian Pembiayaan dengan jumlah pertanyaan sebanyak 12 pertanyaan untuk penelitian ini, maka dapat diuraikan dibawah ini dari hasil wawancara mengenai Penerapan Good Corporate Governance (GCG) pada PT. Bank Aceh Syariah Cabang Kutacane.

Dari hasil penelitian yang telah penulis lakukan di PT. Bank Aceh Syariah Cabang Kutacane, maka diketahui bahwa Good Corporate Governance (GCG) merupakan prinsip-prinsip yang diterapkan oleh perusahaan untuk memaksimalklan nilai perusahaan, meningkakan kinerja dan kontribusi perusahaan serta menjaga keberlanjutan perusahaan secara jangka panjang.

Penerapan Tata Kelola Perusahaan yang Baik (Good Corporate Governance/GCG) telah menjadi landasanyang kuat bagi PT. Bank Aceh Syariah untuk menghadapiperubahan lingkungan bisnis di masa depan. Segalakeputusan strategis yang dilakukan oleh DewanKomisaris dan Direksi selalu mempertimbangkanprinsip-prinsip GCG, yaitu Transparency, Accountability, Responsibility,dan Fairnessyangmerupakan komitmen kuat Bank demi kepentinganpemegang saham dan para pemangku kepentinganlainnya.

1. Prinsip-Prinsip Good Corporate Governance (GCG)

Prinsip-prinsip yang terdapat dalam Good Corporate Governance (GCG) mulai diterapkan oleh PT. Bank Aceh Syariah Cabang Kutacane sejak tahun 2006, yaitu dimulai dari adanya komitmen dari manajemen pada setiap jenjang organisasi dengan cara menetapkan strategic policy dan the code of conduct yang harus dipatuhi oleh semua pihak yang 
berkepentingan dalam perusahaan.Prinsip-prinsip yang dimaksud yaitu Transparency (Keterbukaan), Accountability (Akuntabilitas), Responsibility (Tanggungjawab) dan Fairness (Kewajaran) yang akan dijabarkan di bawah ini :

\section{a. Transparency (Keterbukaan)}

Keterbukaan dalam mengemukakan informasi, baik dalam proses pengambilan keputusan maupun dalam mengungkapkan informasi material dan relevan mengenai perusahaan.Laporan-laporan ke kantor pusat sudah diterapkan oleh PT. Bank Aceh Syariah Cabang Kutacane. Setiap laporan tersebut selalu di kirim dan dilaporkan sesuai prosedurnya secara tepat waktu.

Dalam mengakses laporan-laporan yang diminta oleh nasabah, seperti laporan neraca dan laporan keuangan, nasabah tidak bebas dalam mengakses laporan tersebut. Tidak bebas disini maksudnya adalah dalam batasan-batasan tertentu saja. Misalnya nasabah hanya bisa mengakses neraca atau laporan keuangan secara garis besar saja dan tidak secara detail. Karena hal itu termasuk privasi bank yang bersangkutan. Laporan sistem kerja, kebijakan dan laporan kinerja perusahaan sudah dilaporkan ke Bank Indonesia dan kantor pajak oleh PT. Bank Aceh Syariah Cabang Kutacane secara tepat waktu.

Prinsip ini juga berhubungan dengan beberapa sifat nabi, yaitu sifat tabligh dan amanah. Karena kaitannya dengan kedua sifat nabi ini adalah karyawan bisa memberi laporan yang relevan serta dapat dipercaya.

Salah satu contoh aplikasinya adalah mengungkapkan laporan keuangan yang di posting pada website Bank Aceh dan menampilkan biodata pengurus (Direksi dan
Komisaris) pada laporan tahunan Good Corporate Governance.

b. Accountability (Akukntabilitas)

PT. Bank Aceh Syariah Cabang Kutacane terutama karyawan dam karyawati sudah melakukan job description sebagai acuan kerjanya yang sesuai dengan Code of Conduct (CoC). PT. Bank Aceh Syariah Cabang Kutacane juga menetapkan sanksi bagi karyawan yang melanggar sistem dan ketentuan yang ditetapkan. Sanksi bagi para karyawan yang melanggar sistem dan ketentuan tersebut adalah berupa surat teguran atau Surat Peringatan (SP).

Prinsip ini juga berhubungan dengan salah satu sifat nabi, yaitu sifat fathanah (kecerdasan). Karena kaitannya dengan sifat ini membuat para karyawan bisa mempertanggungjawabkan kinerjanya. Sehingga, para karyawan dalam melaksanakan job description untuk melaksanakan kegiatankegiatannya dalam perbankan sesuai dengan bidangnya masing-masing.

Salah satu contoh aplikasinya adalah PT. Bank Aceh Cabang Kutacane menetapkan rincian tugas (job description) semua karyawan secara jelas dan selaras dengan visi, misi, nilai-nilai perusahaan (corporate values), dan strategi perusahaan.

c. Responsibility (Tanggung Jawab)

Tanggung Jawab yaitu kesesuaian di dalam pengelolaan PT. Bank Aceh Syariah Cabang Kutacane dengan peraturan perundangundangan yang berlaku. PT. Bank Aceh Syariah Cabang Kutacane bertanggungjawab untuk mematuhi hukum dan perundang-undangan yang berlaku, termasuk ketentuan yang berhubungan dengan ketenagakerjaan, perpajakan, persaingan 
Volume 8, Nomor 1, Februari, 2020

usaha yang tidak sehat, kesehatan dan keselamatan kerja, dan lain sebagainya.

PT. Bank Aceh Syariah Cabang

Kutacane sudah patuh terhadap segala regulasi yang diberikan Bank Indonesia dan fatwa Dewan Pengawasan Syariah. PT. Bank Aceh Syariah Cabang Kutacane juga sudah mengupayakan kesejahteraan bagi para karyawannya, seperti pemberian Reward apabila hasil kerja memenuhi target yang ditetapkan. Selain itu dalam upaya kesejahteraan karyawannya, Bank juga memberikan setiap karyawan JAMSOSTEK (Jaminan Sosial Tenaga Kerja).

Hal ini dapat mendukung kesejahteraan para karyawannya. Kemudian untuk dana ZIS (Zakat, Infak, Sedekah), PT. Bank Aceh Syariah Cabang Kutacane menyalurkan dana ZIS tersebut sesuai dengan ketentuan yang berlaku dan setiap penghasilan yang diterima karyawan sudah dipotong zakat.

Prinsip ini juga berhubungan dengan salah satu sifat nabi, yaitu sifat shiddiq (kejujuran). Karena kaitannya dengan sifat ini membuat para karyawan selalu melaksanakan peraturan perundanng-undangan yang telah diberlakukan. Sehingga terciptanya kesejahteraan karyawan, nasabah maupun masyarakat.

Salah satu contoh aplikasinya adalah mengupayakan kesejahteraan karyawannya dengan memberikan setiap karyawan JAMSOSTEK (Jaminan Sosial Tenaga Kerja). Adanya program atau pelaksanakan Coporate Social Responsibility (CSR) atau kepedulian lingkungan.

d. Fairness (Kewajaran)

Kewajaran ialah keadilan dan kesetaraan dalam pemenuhan hak-hak stakeholdersesuai peraturan perundang-undangan yang berlaku. PT. Bank Aceh Syariah Cabang Kutacane sudah memperhatikan kepentingan-kepentingan stakeholdersnya mengenai rasio bagi hasil yaitu dengan adanya pembagian deviden pada setiap tahun.

PT. Bank Aceh Syariah Cabang Kutacane sudah mempertimbangkan pelaksanaan reward dan punishment bagi karyawan dan telah diterapkan bagi semua karyawan. Dalam penerapan sistem peringkat jabatan, karyawan dikontrak dalam jangka waktu minimal 5 tahun dan dalam waktu tersebut karyawan berhak di promosikan. Jika kinerja karyawan baik maka akan dipertimbangkan untuk kenaikan jabatan. Namun jika kinerja karyawan tidak mengalami peningkatan, maka dalam jangka waktu tersebut karyawan tidak dapat promosi kenaikan jabatan.

Prinsip ini juga berhubungan dengan salah satu sifat nabi, yaitu sifat fathanah (kecerdasan). Karena kaitannya dengan sifat ini membuat para karyawan terus mengupayakan yang terbaik dalam meningkatkan kinerjanya pada Bank.

Salah satu contoh aplikasinya adalah memperlakukan setiap karyawan secara adil dan bebas dari bias karena perbedaan suku, agama, asal-usul, jenis kelamin atau hal-hal lain yang tidak ada kaitannya dengan kinerja.

2. Kendala yang dihadapi PT. Bank Aceh Syariah Cabang Kutacane dalam menerapkan prinsip Good Corporate Governance (GCG).

Untuk kendala yang dihadapi dalam menerapkan Good Corporate Governance (GCG) yang seharusnya diterapkan pada PT. Bank Aceh Syariah Cabang Kutacane tidak ada. Sejauh ini, 
PT. Bank Aceh Syariah Cabang Kutacane terus melakukan melakukan yang terbaik.

3. Kesesuaian Penerapan Good Corporate Governance (GCG) dan Prinsip-Prinsip Syariah yang Mendukung.

Dalam ketentuan Good Corporate Governance (GCG), PT. Bank Aceh Syariah Cabang Kutacane sudah bersesuaian dengan prinsip-prinsip syariah Islam seperti sifat Shiddiq (kejujuran) yang sudah diterapkan dengan selalu memberikan informasi yang benar terhadap semua transaksi nasabah. Sifat Amanah (kepercayaan) juga sudah diterapkan yaitu dalam bentuk setiap simpanan nasabah diberikan hak bagi hasil sesuai dengan kesepakatan tanpa mengurangi sedikit pun.

Dalam penerapan sistem peringkat jabatan, Perusahaan membuat sistem jenjang karir (career path) yang dimulai dari OJT (On Job Training) minimal 3 bulan dan maksimal 6 bulan. Jika kinerja karyawan baik maka akan dilanjutkan dengan Kontrak 1 selama 1 tahun kemudian Konrak 2 selama 1 tahun. Jika kinerja karyawan terus meningkat maka karyawan akan diangkat sebagai pegawai tetap.

Setelah menjadi pegawai tetap, karyawan akan dipromosikan untuk naik jabatan minimal 5 tahun sekali pada setiap karyawan. Jika kinerja karyawan baik maka besar kemungkinan karyawan untuk naik jabatan. Namun jika kinerja tidak meningkat maka karyawan akan tetap pada jabatannya.

\section{KESIMPULAN}

penelitian ini dapat disimpulkan bahwa penerapan Good Corporate Governance (GCG) pada PT. Bank Aceh Syariah Cabang Kutacane sudah menjalankan dan menerapkannya dengan baik. Berdasarkan pada empat prinsip yang terdapat dalam Good Corporate Governance (GCG) yaitu Transparency (keterbukaan), Accouontability (akuntabilitas), Respobsibility (tanggungjawab) dan Fairness (kewajaran) yang sesuai dengan peraturan perundang-undangan yang diterapkan oleh Bank Indonesia.

Prinsip-prinsip syariah yang mendukung pada PT. Bank Aceh Syariah Cabang Kutacane juga sudah dijalankan dan diterapkan dengan baik. Prinsip syariah tersebut adalah sifat nabi yang antara lain, shiddiq (kejujuran), amanah (kepercayaan), fathanah (kecerdasan) dan tabligh (keterbukaan).

Selama menjalankan dan menerapkan Good Corporate Governance (GCG), tidak terdapat kendala-kendala yang dihadapi oleh PT. Bank Aceh Syariah Cabang Kutacane. Oleh karena itu, sejauh ini PT. Bank Aceh Syariah Cabang Kutacane terus melakukan yang terbaik.

Ketentuan Good Corporate Governance (GCG) yang bersesuaian dengan prinsip-prinsip syariah Islam selalu dijalankan sesuai dengan prosedur yang baik oleh PT. Bank Aceh Syariah Cabang Kutacane.

\section{DAFTAR PUSTAKA}

Amin, Fadillah. 2016. Antologi Administrasi Publik dan Pembangunan : Festschrift untuk Sjamsiar. Malang : UB Press.

Ardhanareswani. 2014. "GCG ASIA TENGGARA:Menyedihkan, Peringkat RI Nomor Dua Dari Bawah”. 28 Juni 2018. http://market.bisnis.com/read/20140429/7/22 3481/gcg-asia-tenggara-menyedihkanperingkat-rinomor-dua-dari-bawah. 
Volume 8, Nomor 1, Februari, 2020

Ardy. 2016. Analisis Penerapan Prinsip-Prinsip Good Corporate Governance Pada PT Cahaya Mutiara Farma. Jurnal Manajemen Bisnis. Vol. 4., No. 2.

Arwani, Agus. 2016. Akuntansi Perbankan Syariah Dari Teori ke Praktik (Adopsi IFRS). Yogyakarta : Deepublish (CV Budi Utama).

Arikunto, Suharsimi. 2013. Metodologi Penelitian.

Yogyakarta: Bina Aksara.

Azheri, Busyra. 2014. Corporate Social Responsibillity. Jakarta : PT RajaGrafindo Persada.

Bank Aceh. 2017. Laporan Tahunan Bank Aceh Syariah.

Basri, Faisal dan Munandar, Haris. 2013. Lanskap

Ekonomi Indonesia. Jakarta : Kencana Prenada Media Group.

Daniri, Mas Achmad. 2014. Lead by GCG. Jakarta : Gagas Bisnis Indonesia.

Effendi, Arief. 2016. The Power of Good Corporate Governance Teori dan Implementasi. Jakarta : Salemba Empat.

Friendly, Eric. 2017. Analisis Penerapan Prinsip-

Prinsip Good Corporate Governance Pada Perusahaan Milik Keluarga Bidang Perhotelan. Jurnal Manajemen Bisnis. Vol. 5., No. 3.

Halimatusakdiah, Elly dan Gunwan, Bangun. 2014. Analisis Penerapan Good Corporate Governance Dalam Pengoptimalkan Pelaksanaan Sistem Informasi Akuntansi (Studi Pada PT POS Indonesia (Persero)). Jurnal Riset Akuntansi Dan Keuangan. Vol. 2., No. 1.

Hamid, Ahmad dan Mukhlis Yunus, Sulaiman. 2015. Pengaruh Penerapan Good Corporate Governance Terhadap Kinerja Pegawai dan
Dampaknya Terhadap Kinerja Dinas

Pertanian dan Peternakan Kabupaten Bireun. Jurnal Manajemen Pascasarjana. ISSN : 2302-0199., Vol. 4., No. 4.

Hati, Shinta Wahyu dan Arumrasmy, Awik. 2017. Analisis Penerapan Prinsip Good Corporate Governance Terhadap Kinerja Pegawai Di Politeknik Negeri Batam. Jurnal Administrasi Bisnis.

Idris, M. 2015. Ini Daftar Emiten dengan Predikat GCG Terbaik di 2015.

Ifham, Ahmad. 2015. INI LHO BANK SYARIAH! Memahami Bank Syariah dengan Mudah. Jakarta : PT Gramedia.

Luwi, Asnawi. "Bank Aceh Syariah Cabang Kutacane Gelar Pasar Murah Lima Kecamatan”.30Agustus2018.https://www.go ogle.co.id/amp/aceh.tribunnews.com/amp/20 18/05/30/bank-aceh-syariah-cabangkutacane-gelar-pasar-murah-limakecamatan.

Mardani. 2015. Aspek Hukum Lembaga Keuangan Syariah di Indonesia. Jakarta : Kencana.

Mutamimah dan Phradiansah. 2014. Analisis Implementasi Good Corporate Governance Terhadap Kinerja SDM Melalui Organizational Commitment. Jurnal Ekonomi Bisnis. Vol. 15., No. 2.

Prasetyantoko, A. 2015. Corporate GovernancPendekatan institusional. Jakarta : PT Gramedia.

Pratiwi, Angrum. 2016. Pengaruh Kualitas Penerapan Good Corporate Governance (GCG) Terhadap Kinerja Keuangan Pada Bank Umum Syariah Di Indonesia (Periode 2010-2015). Jurnal Ekonomi dan Bisnis 
Islam. P-ISSN : 2460-9404., E-ISSN : 24609412., Vol. 2., No.1.

Rivai, Veithzal., Veithzal, Andria Permata dan Idroes, Ferry N. 2014. Bank and Financial Institution Management Conventional \& Sharia System. Jakarta : PT Raja Grafindo Persada.

Said, Achmad Lamo. 2015. Corporate Social Responsibility dalam Perspektif Governance. Yogyakarta : Deepublish (CV Budi Utama).

Sedarmayanti. 2014. Good Covernance (Kepemerintahan Yang Baik). Bandung : Mandar Maju.
Sekaran, Uma dan Bougie, Roger. 2017. Metode Penelitian Untuk Bisnis. Jakarta : Salemba Empat.

Soemitra, Andri. 2015. Bank \& Lembaga Keuangan Syariah. Jakarta : Prenadamedia Group.

Sugiyono. 2015. Metode Penelitian Kuantitatif, Kualitatif dan R\&D. Bandung : Alfabeta. Sutedi, Adrian. 2017. Good Corporate Governance. Jakarta : Sinar Grafika. 